\title{
DLECI is a functional 3p22.3 tumour suppressor silenced by promoter CpG methylation in colon and gastric cancers
}

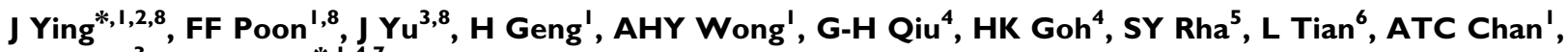 \\ JJY Sung ${ }^{3}$ and $Q$ Tao*,i,4,7
}

'Cancer Epigenetics Laboratory, Department of Clinical Oncology, State Key Laboratory in Oncology in South China, Sir YK Pao Center for Cancer, Hong Kong Cancer Institute and Li Ka Shing Institute of Health Sciences, Chinese University of Hong Kong, Shatin, Hong Kong, China; ${ }^{2}$ Department of Pathology, Cancer Institute and Cancer Hospital, Peking Union Medical College (PUMC), Chinese Academy of Medical Sciences, Beijing, China;

${ }^{3}$ Department of Medicine and Therapeutics, Institute of Digestive Disease, Chinese University of Hong Kong, Shatin, Hong Kong, China; ${ }^{4}$ Johns Hopkins Singapore, Singapore; ${ }^{5}$ Yonsei Cancer Center, Yonsei University College of Medicine, Seoul, Korea; ${ }^{6}$ Stanley Ho Center for Emerging Infectious Disease, Chinese University of Hong Kong, Shatin, Hong Kong, China; ' 5 Sidney Kimmel Comprehensive Cancer Center, Johns Hopkins School of Medicine, Baltimore, MD, USA

Promoter CpG methylation of tumour suppressor genes (TSGs) is an epigenetic biomarker for TSG identification and molecular diagnosis. We screened genome wide for novel methylated genes through methylation subtraction of a genetic demethylation model of colon cancer (double knockout of DNMTI and DNMT3B in HCTI I6) and identified DLECI (Deleted in lung and oesophageal cancer I), a major 3p22.3 TSG, as one of the methylated targets. We further found that DLECI was downregulated or silenced in most colorectal and gastric cell lines due to promoter methylation, whereas broadly expressed in normal tissues including colon and stomach, and unmethylated in expressing cell lines and immortalised normal colon epithelial cells. DLECI expression was reactivated through pharmacologic or genetic demethylation, indicating a DNMTI/DNMT3B-mediated methylation silencing. Aberrant methylation was further detected in primary colorectal (10 out of 34, 29\%) and gastric tumours (30 out of 89, 34\%), but seldom in paired normal colon (0 out of 17) and gastric (I out of 20,5\%) samples. No correlation between DLECI methylation and clinical parameters of gastric cancers was found. Ectopic expression of DLECI in silenced HCTII6 and MKN45 cells strongly inhibited their clonogenicity. Thus, DLECI is a functional tumour suppressor, being frequently silenced by epigenetic mechanism in gastrointestinal tumours.

British Journal of Cancer (2009) 100, 663-669. doi:10.1038/sj.bjc.6604888 www.bjcancer.com

Published online 20 January 2009

(c) 2009 Cancer Research UK

Keywords: tumour suppressor gene (TSG); DLECI; CpG island; methylation; colon and gastric cancers

Tumorigenesis is a multistep process, with colorectal cancer (CRC) as the prototype model for multi-step genetic pathogenesis (Kinzler and Vogelstein, 1996). In this model, the key molecular event is the inactivation of multiple tumour suppressor genes (TSGs) due to genetic alterations. Also, it is now well established that alternative epigenetic silencing, such as methylation of promoter CpG islands (CGIs), leads to the inactivation of TSGs in virtually all tumour types and plays significant roles in tumour initiation and progression (Jones and Baylin, 2002). In CRC, epigenetic silencing of multiple TSGs has been reported frequently, including $M L H 1$, p16 ${ }^{I N K 4 A}, M G M T, V H L, A P C, R A S S F 1 A, H I C 1$,

\footnotetext{
*Correspondence: Dr Q Tao, Department of Clinical Oncology, PWH, Chinese University of Hong Kong, Shatin, Hong Kong, China;

E-mail: qtao@clo.cuhk.edu.hk

Dr J Ying, Department of Pathology, Cancer Institute and Cancer Hospital, Peking Union Medical College (PUMC), Chinese Academy of Medical Sciences, Beijing, China; E-mail: jmying@hotmail.com

${ }^{8}$ These authors contributed equally to this work.

Received 7 July 2008; revised II December 2008; accepted 17 December 2008; published online 20 January 2009
}

CHFR, ADAMTS18 and PCDH10 in various percentages of CRC tumours (Herman et al, 1998; Esteller et al, 2001; Kim et al, 2005; Ying et al, 2006; Jin et al, 2007 ). A growing list of TSGs with CGI methylation-mediated silencing has also been reported in gastric cancer (Leung et al, 2001). It is important to identify more new TSGs that are silenced by tumour-specific methylation in CRC and gastric cancers, which could serve as valuable biomarkers for molecular diagnosis and also provide clues to the molecular pathogenesis of these tumours.

In this study, we conducted a genome-wide search for genes with promoter methylation in CRC, by utilising CpG methylationspecific subtraction, in a CRC model of HCT116 cells deficient in DNMT1 and DNMT3B (double knockout (DKO) cells). DNMT1 and DNMT3B are the two major DNA methyltransferases responsible for the maintenance and de novo $\mathrm{CpG}$ methylation, and the disruption of these two genes results in more than $95 \%$ loss of overall genomic methylation and CGI demethylation (Rhee et al, 2002). Virtually all known TSGs with methylation-mediated silencing in HCT116 became demethylated and reactivated in HCT116DKO, making it a good epigenetic model to identify novel candidate TSGs silenced in tumours (Rhee et al, 2002; Paz et al, 2003; Ying et al, 2005). Among the methylated target genes we 
identified, one is DLEC1 (Deleted in lung and oesophageal cancer 1), located at $3 \mathrm{p} 22.3$ - a common tumour suppressor locus with frequent genetic abnormalities in multiple cancers (Imreh et al, 2003). The expression of DLEC1 and its regulation in digestive tumours have yet to be evaluated. We found that DLEC1 underwent promoter methylation-associated silencing in most CRC and gastric tumour cell lines and primary tumours, in a tumour-specific manner. Reintroduction of DLEC1 into silenced tumour cells significantly suppressed tumour cell clonogenicity.

\section{MATERIALS AND METHODS}

\section{Cell lines and primary tumours}

Seven CRC (HCT116, HT29, LoVo, SW480, DLD1, LS180 and SW620) and 17 gastric cancer (Kato III, YCC1, YCC2, YCC3, YCC6, YCC7, YCC9, YCC10, YCC11, YCC16, SNU719, AGS, MKN28, NCI87, SNU1, SNU16 and MKN45) cell lines were used. Cell lines were routinely maintained in RPMI-1640 medium with $10 \%$ FBS. HCT116 cell line with genetic knockout of DNA methyltransferase genes (DNMTs): HCT116 DNMT1-/- (DNMT1KO), HCT116 DNMT3B-/- (DNMT3BKO) and HCT116 DNMT1-IDNMT3B-/- (DKO) (gift from Dr Bert Vogelstein, Johns Hopkins) were grown with either $0.4 \mathrm{mg} \mathrm{ml}^{-1}$ genecitin or $0.05 \mathrm{mg} \mathrm{ml}^{-1}$ hygromycin or both (Rhee et al, 2002). DNA and total RNA were extracted from cell lines using TRI REAGENT (Molecular Research Center, Cincinnati, OH, USA). Genomic DNA of another five CRC cell lines (HCT15, RKO, SW48, Caco-2 and Colo205) and one immortalised normal colon epithelial cell line CCD-841 was also used. Genomic DNA samples from primary tumour tissues of $34 \mathrm{CRC}$ and 89 gastric cancer patients were also used, with DNA samples of matched surgical marginal normal tissue samples from $17 \mathrm{CRC}$ and 20 gastric cancer patients also available. Clinical information was available for all gastric cancer patients, including gender, differentiation, histological type according to Laurén and tumour, node and metastasis (TNM) stage. However, no survival data were available.

\section{Pharmacologic demethylation}

Cell lines with silenced DLEC1 were treated with $5 \mu \mathrm{m}$ of 5 -aza2 -deoxycytidine (Aza) (Sigma, St Louis, MO, USA) for 3 days as described earlier (Ying et al, 2005). After the treatment, cells were pelleted, with DNA and total RNA extracted.

\section{Modified methylation-sensitive representational difference analysis}

To identify novel methylated TSGs, we employed a strategy of modified methylation-sensitive representational difference analysis (MS-RDA), using uracil-DNA glycosylase-based digestion during MS-RDA (Sugai et al, 1998; Kaneda et al, 2003), for DNA samples of the wild-type and DNA methyltransferases (DNMT1 and -3B) DKO of HCT116 (Rhee et al, 2002). The method was based on the principle that restriction enzymes (HpaII, SacII and NarI) have different sensitivities towards sequences containing 5-methyl cytosine (CCGG, CCGCGG and GGCGCC). We further selected candidate genes with typical promoter CGI and also located at important chromosome loci commonly deleted in tumours and possibly harbouring putative TSGs for more detailed studies, such as DLEC1.

\section{Semi-quantitative reverse transcription PCR}

Reverse transcription PCR (RT - PCR) was performed as described earlier (Tao et al, 2002; Ying et al, 2006), using GAPDH as a control. The primers for DLEC1 are listed in Table 1. The PCR programme utilised an initial denaturation at $95^{\circ} \mathrm{C}$ for $10 \mathrm{~min}$, followed by 33 cycles of reaction $\left(94^{\circ} \mathrm{C}\right.$ for $30 \mathrm{~s}, 55^{\circ} \mathrm{C}$ for $30 \mathrm{~s}$ and $72^{\circ} \mathrm{C}$ for $30 \mathrm{~s}$ ), with a final extension at $72^{\circ} \mathrm{C}$ for $10 \mathrm{~min}$.

\section{Bisulphite treatment and promoter methylation analysis}

Bisulphite modification of DNA was carried out as described earlier using $2.4 \mathrm{M}$ sodium metabisulphite (Tao et al, 2002). Methylation-specific PCR (MSP) and bisulphite genomic sequencing (BGS) were conducted according to our earlier reports (Tao et al, 1999; Ying et al, 2006). Methylation-specific PCR primers are listed in Table 1 . Methylation-specific PCR was conducted at $95^{\circ} \mathrm{C}$ for $10 \mathrm{~min}$, followed by 40 cycles of reaction $\left(94^{\circ} \mathrm{C}, 30 \mathrm{~s} ; 58^{\circ} \mathrm{C}\right.$ for $\mathrm{M}, 55^{\circ} \mathrm{C}$ for $\mathrm{U}, 30 \mathrm{~s} ; 72^{\circ} \mathrm{C}, 30 \mathrm{~s}$ ), ended by $72^{\circ} \mathrm{C}$ for $5 \mathrm{~min}$. Methylation-specific PCR primers were tested earlier for not amplifying any non-bisulphite-treated genomic DNA and thus specific. The MSP products of selected samples have been confirmed by direct sequencing. The top strand-specific BGS primers for bisulphite-converted single-stranded DNA of the DLEC1 promoter are listed in Table 1. Amplified products were cloned into the pCR4-Topo vector (Invitrogen, Carlsbad, CA, USA), with six to eight colonies randomly chosen and sequenced.

\section{Cloning of the human DLEC1 full-length open reading frame}

Four pairs of primers were used to generate four DLEC1 fragments based on the published DLEC1 sequence (GenBank accession number AB020522): I, II, III and IV, which contain restriction enzyme sites of $M f e I, N d e I$ and $A p a L I$, respectively. The sequences of primers for these fragments are listed in Table 1. Reverse transcription was carried out using normal human testis RNA as a template (BD Biosciences, Palo Alto, CA, USA). Reverse transcription PCR products were cloned into pCR II-TOPO vector (Invitrogen) with the sequences and orientations confirmed from both ends. The four fragments were then ligated to form the fulllength DLEC1 cDNA, which was then cloned into the pcDNA3.1 vector, using the restriction sites BamHI and $M f e I$ (vector and fragment I), $M f e \mathrm{I}$ and $N d e \mathrm{I}$ (fragment II), NdeI and ApaLI (fragment III), and ApaL I and Xho I (fragment IV and vector), to generate the recombinant vector pcDNA3.1-DLEC1.

\section{Colony formation assay}

Cells $\left(1.5 \times 10^{5}\right.$ per well). were plated in a 12 -well plate and transfected with either expression plasmid or the empty vector $(0.8 \mu \mathrm{g}$ each), using FuGENE 6 (Roche Diagnostics, Mannheim, Germany). Forty-eight hours post-transfection, cells were collected and plated in a six-well plate, and selected for 2 weeks with G418 $\left(0.4 \mathrm{mg} \mathrm{ml}^{-1}\right)$. Surviving colonies ( $\geqslant 50$ cells per colony) were counted after staining with Gentian Violet. Total RNA from the transfected cells was extracted, treated with TURBO DNase (Ambion, Austin, TX, USA) and analysed by RT - PCR to confirm the ectopic expression of DLEC1. All the experiments were performed in triplicate wells for three times.

\section{Statistical analysis}

Chi square test was used to analyse possible correlation between clinical parameters and DLEC1 methylation status of tumour and non-tumour samples. For colony formation assay, experimental differences were tested for statistical significance using $t$-test. All analyses were performed using SAS for windows, version 9 software (SAS Institute Inc., Cary, NC, USA). A $P$-value of $<0.05$ was considered significant. 
Table I List of primers used in this study

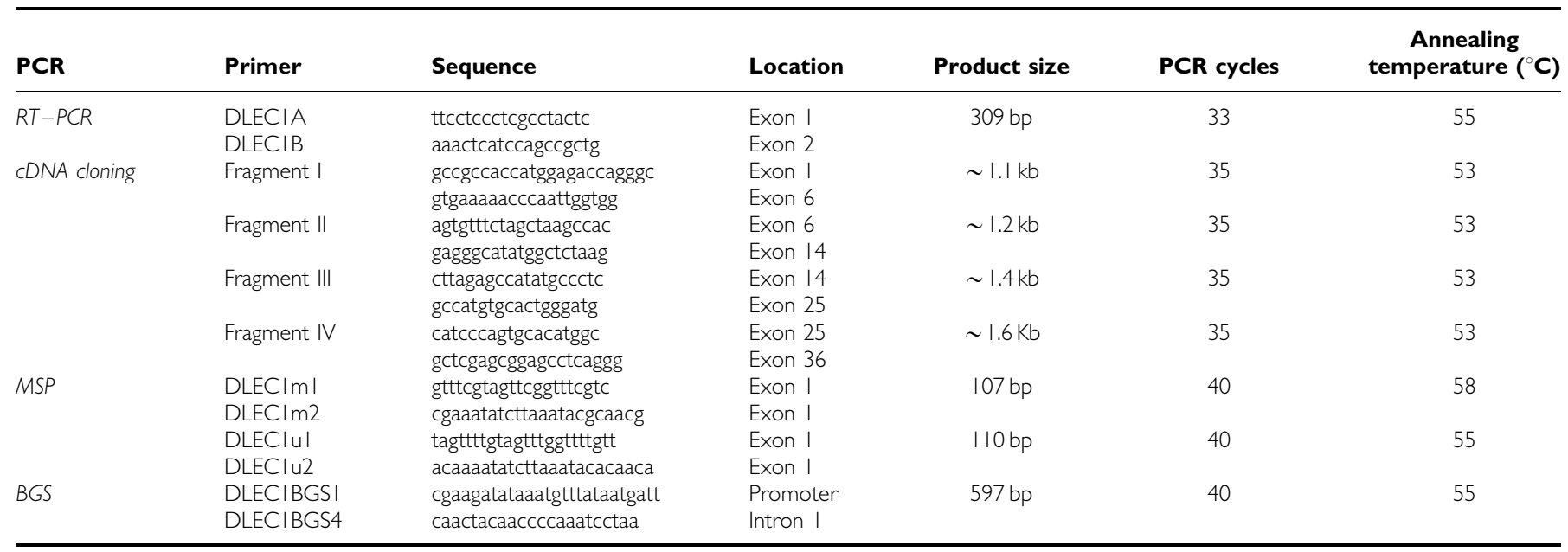

$\mathrm{BGS}=$ bisulphite genomic sequencing; $\mathrm{MSP}=$ methylation-specific PCR.

A
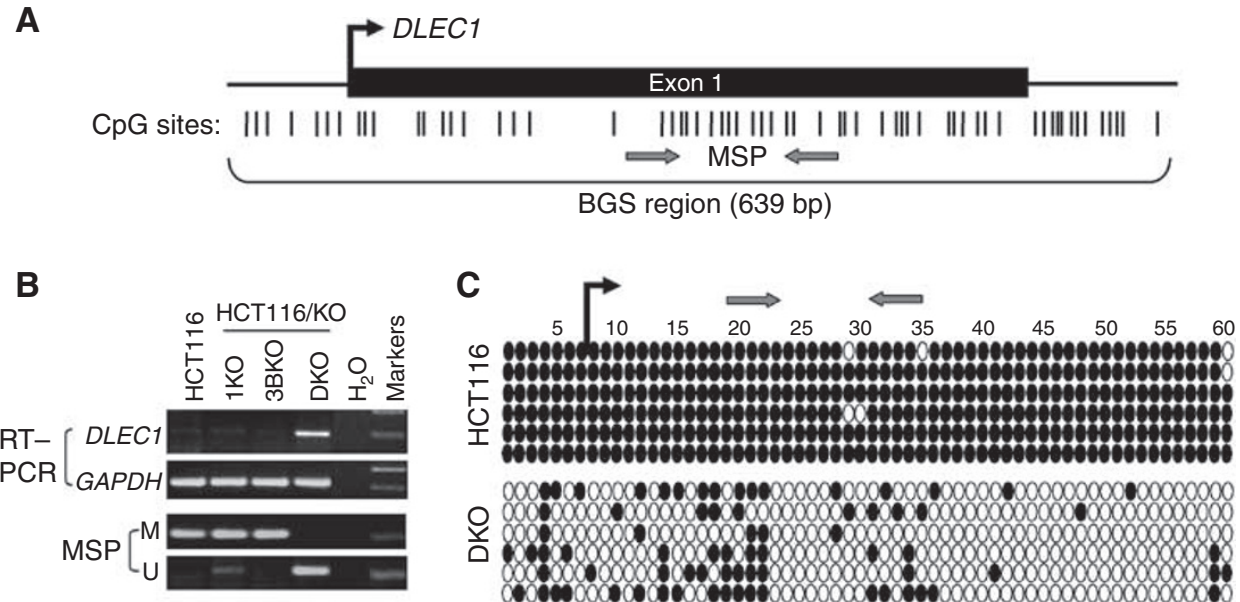

Figure I Identification of DLECI as a methylated gene in CRC (HCTI I6) cells. (A) Schematic illustration of the DLECI promoter and its CGI. Locations of the exon I (indicated with a long rectangle) and CpG sites (short vertical lines) in the CGI are shown. The transcription start site is indicated by a curved arrow. (B) Genetic demethylation reactivated DLECI expression in DKO cells. U: unmethylated; M: methylated. (C) Detailed BGS analysis confirmed the MSP results. Methylation status of each individual promoter allele was shown as a row of CpG sites sequenced from each bacterium colony. Filled circle, methylated; open circle, unmethylated.

\section{RESULTS}

\section{Epigenetic identification of DLEC1 as a methylated gene in CRC}

Using a modified MS-RDA to screen genome wide for methylated sequences in HCT116 and its demethylated DKO cells, we identified 22 hypermethylated DNA fragments/genes (Ying and Tao, manuscript in preparation). Among these identified sequences, one of particular interest is DLEC1, a candidate TSG previously identified in lung cancer (Daigo et al, 1999). Although no methylation was detected in this first report, the region spanning the putative promoter and exon 1 of DLEC1 is a typical CGI (Gardiner-Garden and Frommer, 1987) (Figure 1A) that is susceptible to epigenetic silencing. We designed MSP and BGS primers to analyse its methylation status. Methylation-specific PCR analyses showed that DLEC1 was completely methylated in HCT116 and became completely demethylated in DKO cells, but only marginally demethylated in DNMT1KO and not demethylated in DNMT3BKO cells. Correlated with its methylation status, DLEC1 was silenced in HCT116, and only reactivated in DKO cells, but not in DNMT1KO or DNMT3BKO cells (Figure 1B). Detailed BGS analysis, revealing the methylation status of individual $\mathrm{CpG}$ site of the DLEC1 promoter, showed that only few scattered CpG sites remained methylated in DKO cells whereas HCT116 was almost completely methylated (Figure 1C). These results thus demonstrate a close relationship between the silencing of DLEC1 and its promoter methylation in HCT116 and DKO cells.

\section{Frequent methylation-associated silencing of DLEC1 in CRC and gastric cell lines}

To further examine the correlation of DLEC1 methylation and silencing, we investigated additional human tissues and gastrointestinal cell lines. DLEC1 was found to be readily expressed in all 22 normal adult and 9 foetal tissues including colon, rectum and stomach, with the highest level in testis and weak expression in skeletal muscle and pancreas (Figure 2A), in agreement with the earlier study that this gene is expressed in all tissues examined and abundantly in testis (Daigo et al, 1999). In contrast, DLEC1 was silenced or downregulated in six of seven CRC and 15 of 17 gastric cancer cell lines (Figure 2B). By MSP, DLEC1 methylation was 
A

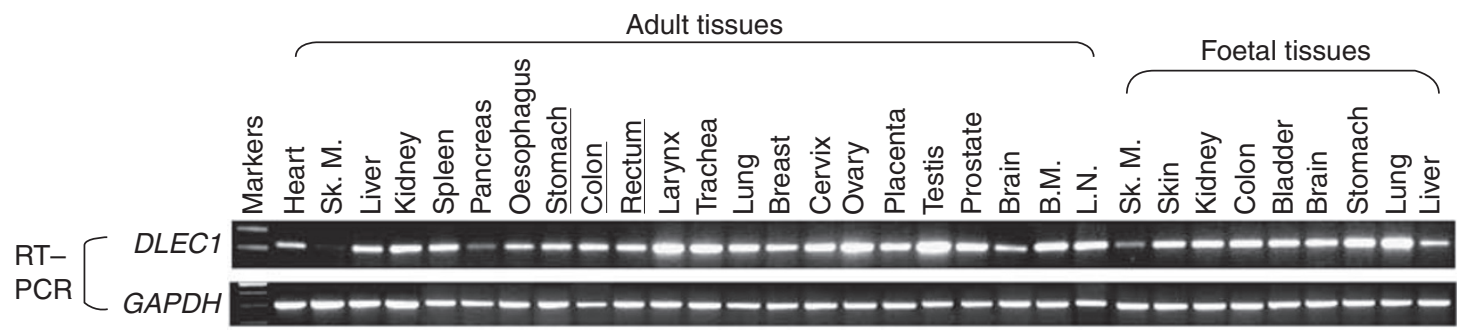

B
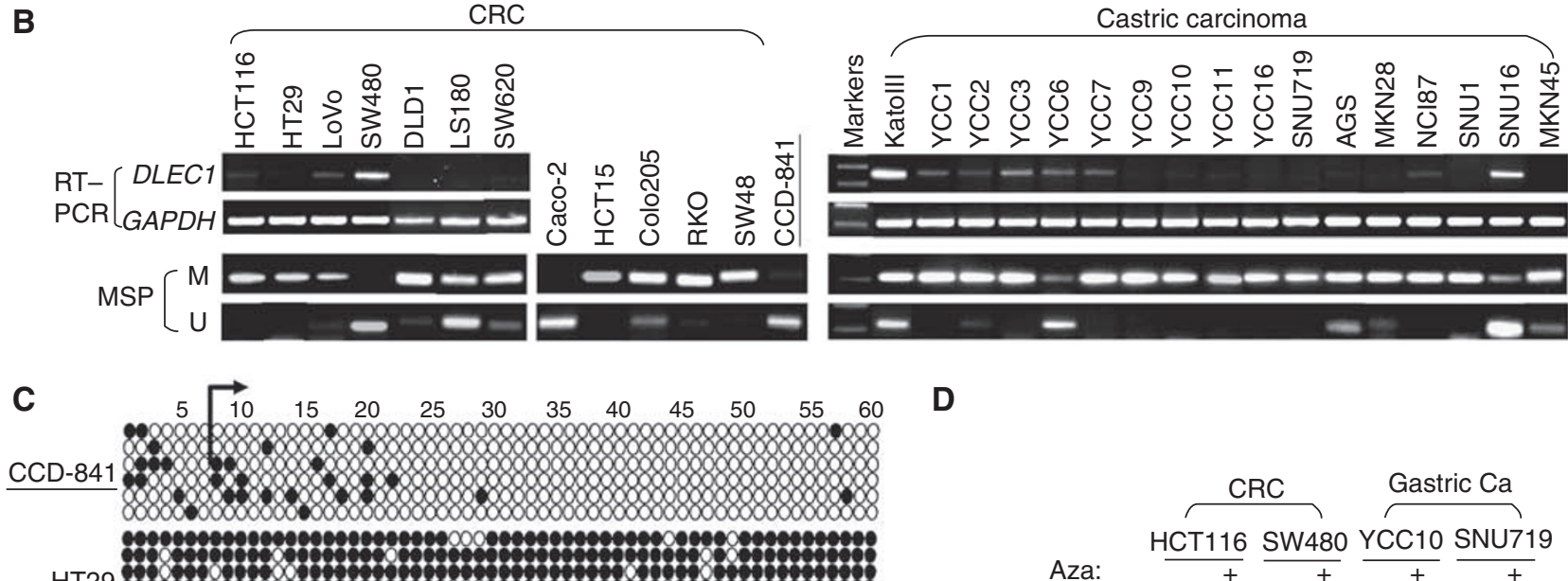

HT29

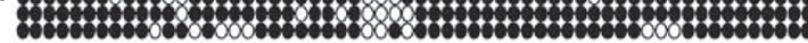
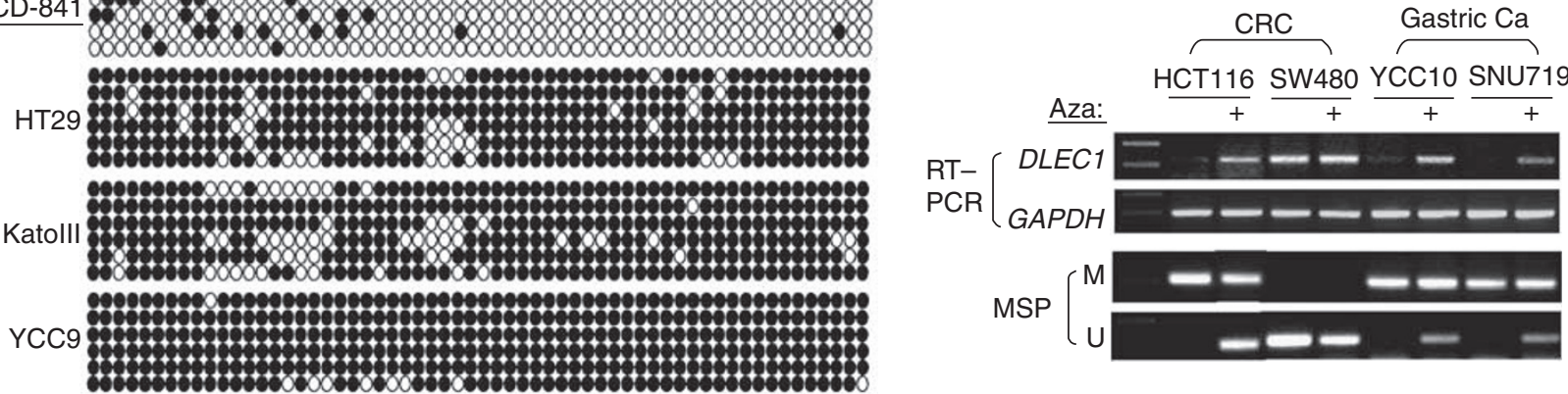

Figure 2 Frequent methylation-associated silencing of $D L E C I$ in $C R C$ and gastric cancer cell lines. (A) Expression profile of DLECI in human normal adult and foetal tissues by semi-quantitative RT-PCR, with GAPDH as a control. Sk M, skeletal muscle; BM, bone marrow; LN, lymph node. (B) Methylation status and expression levels of DLECI in a panel of CRC and gastric cancer cell lines. CCD-84I is an immortalised normal colon epithelial cell line. M, methylated; $\mathrm{U}$, unmethylated. (C) Detailed BGS analysis confirmed the MSP results, as in Figure IC. (D) Reactivation of DLECI by Aza treatment (+), accompanied with demethylation of its promoter CGl.

detected in $83 \%$ ( 10 out of 12 ) of CRC and $100 \%$ (17 out of 17) of gastric cancer cell lines, with complete methylation detected in most cell lines, whereas no methylation was seen in the normal colon epithelial cell line CCD-841 (Figure 2B). Further BGS methylation analysis for one $\mathrm{CRC}$, two gastric cell lines and CCD-841 confirmed the MSP results, with a high density of methylated $\mathrm{CpG}$ sites detected in all tumour cell lines, but not in CCD-841 (Figure 2C). Thus, the results revealed a strong correlation between DLEC1 transcriptional silencing and its promoter methylation in virtually all CRC and gastric cancer cell lines examined, except for one CRC cell line LS180, which has both methylated and unmethylated promoter alleles but DLEC1 expression is totally silenced, indicating that other mechanisms such as histone modification also could not be excluded.

\section{Restoration of DLEC1 expression by pharmacologic demethylation}

To determine whether methylation directly mediates the silencing of DLEC1, two CRC (HCT116 - methylated, SW480 - unmethylated) and two methylated gastric (YCC10 and SNU719) cancer cell lines were treated with Aza, a DNA methyltransferase inhibitor. After the treatment, DLEC1 expression was restored in methylated cell lines along with an obvious increase of unmethylated promoter alleles (Figure 2D). In contrast, no significant change of DLEC1 expression and methylation levels was observed in the unmethylated cell line SW480, indicating that Aza treatment did not cause indirect reactivation effect. Together with earlier results of DLEC1 reactivation after genetic demethylation in DKO cells, these results showed that methylation of the DLEC1 promoter directly leads to its silencing in CRC and gastric cancers.

\section{Frequent DLEC1 methylation in primary CRC and gastric} tumours

The methylation status of $D L E C 1$ was further examined in primary CRC and gastric tumour samples using the well-validated MSP analysis. Aberrant methylation was detected in 10 out of $34(29 \%)$ of CRC and 30 out of 89 (34\%) of gastric tumours, but seldom in paired normal gastric tissues (1 out of 20,5\%) nor any of the paired normal colon tissue samples (0 out of 17) (Figure 3A). Further BGS analysis revealed densely methylated promoter alleles in primary tumours, whereas only scattered methylated $\mathrm{CpG}$ sites in paired normal tissues (Figure $3 \mathrm{~B}$ ). Thus, promoter methylation of DLEC1 is a frequent and tumour-specific epigenetic abnormality in CRC and gastric cancer.

Although the frequency of DLEC1 methylation in gastric cancer was high (34\%), no correlations between DLEC1 methylation status and gender, tumour location, Lauren type, tumour differentiation and TNM stage were found (Table 2). 

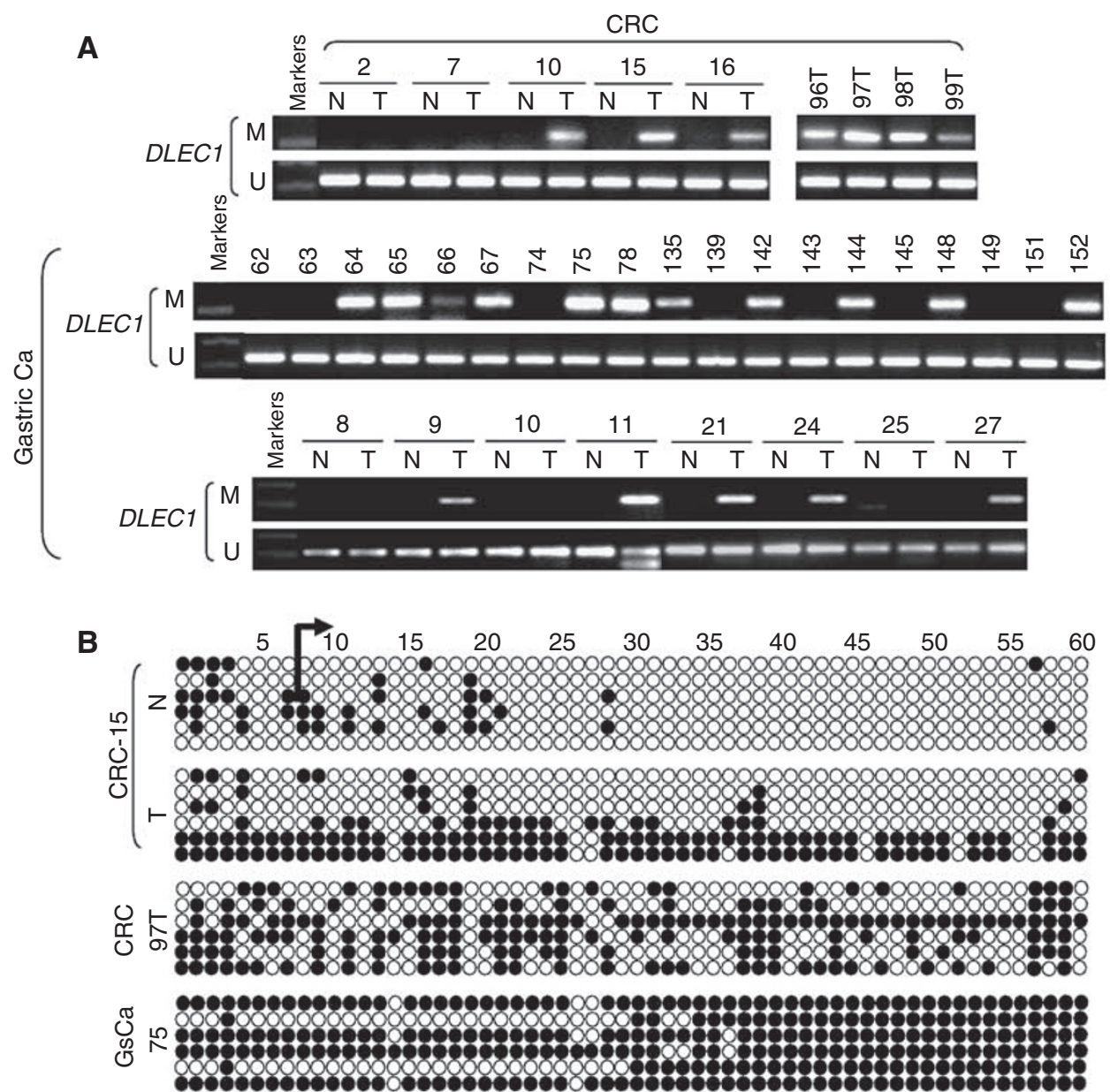

Figure 3 DLECI methylation in primary CRC and gastric tumours. (A) Representative results of DLECI methylation as detected by MSP in tumours (T), but not in the paired normal tissues (N). U: unmethylated; M: methylated. (B) High-resolution methylation mapping of individual CpG sites in the DLECI CGI by BGS. GsCa: gastric carcinoma.

Ectopic expression of DLEC1 suppresses colorectal and gastric tumour cell clonogenicity

The frequent silencing of DLEC1 by methylation in colon and gastric cancer cell lines as well as primary tumours suggested that $D L E C 1$ is a potential tumour suppressor for these tumours. We thus investigated the tumour suppressor function of DLEC1 by colony formation assay. The CRC cell line HCT116 and gastric carcinoma cell line MKN45 with silenced DLEC1 were transfected with DLEC1-expressing vector pcDNA3.1-DLEC1. A strong reduction of colonies (i.e., down to 17 and $37 \%$ of the controls in HCT116 and MKN45 cells, respectively, $P<0.01)$ was observed in cells transfected with pcDNA3.1-DLEC1, compared with the empty vector control (Figure 4). These results indicate that DLEC1 indeed has growth inhibitory activities and could function as a tumour suppressor for colorectal and gastric cancer cells.

\section{DISCUSSION}

This is the first report to identify DLEC1 as a methylated candidate TSG for CRC and gastric cancer. We demonstrated that DLEC1 was absent in most colorectal and gastric cell lines due to promoter methylation, and methylated in a significant part of primary CRC and gastric tumours in a tumour-specific manner. In addition, the
Table 2 Clinicopathologic features of DLECI methylation in gastric cancer

\begin{tabular}{|c|c|c|c|c|c|}
\hline Variable & $\begin{array}{l}\text { Methylated } \\
(n=30)\end{array}$ & $\%$ & $\begin{array}{c}\text { Non- } \\
\text { methylated } \\
(n=59)\end{array}$ & $\%$ & $P$-value \\
\hline \multicolumn{6}{|l|}{ Gender } \\
\hline Male & 20 & 40.8 & 29 & 59.2 & 0.843 \\
\hline Female & 10 & 38.5 & 16 & 61.5 & \\
\hline \multicolumn{6}{|l|}{ Location } \\
\hline Corpus & 23 & 35.9 & 41 & 64.1 & 0.476 \\
\hline Antrum & 7 & 28.0 & 18 & 72.0 & \\
\hline \multicolumn{6}{|l|}{ Lauren } \\
\hline Diffuse & 4 & 18.2 & 18 & 81.8 & 0.131 \\
\hline Intestinal & 19 & 35.8 & 34 & 64.2 & \\
\hline \multicolumn{6}{|l|}{ Differentiation } \\
\hline Poor (or no differentiation) & 19 & 38.0 & 31 & 62.0 & 0.422 \\
\hline Well or moderate & 11 & 29.7 & 26 & 70.3 & \\
\hline \multicolumn{6}{|c|}{ TNM (tumour, node, metastasis) stage } \\
\hline $\mathrm{i}$ and ii & 15 & 38.5 & 24 & 61.5 & 0.440 \\
\hline iii and iv & 15 & 30.6 & 34 & 69.4 & \\
\hline
\end{tabular}



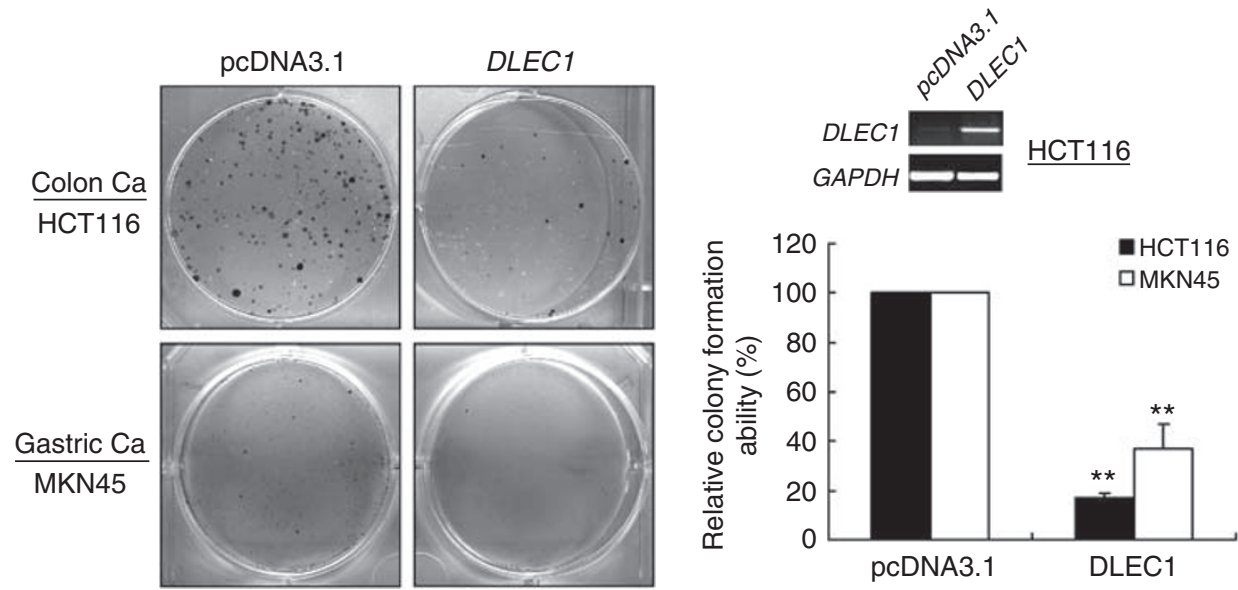

Figure 4 Ectopic DLECI expression suppressed tumour cell clonogenicity of HCTI 16 and MKN45 cells. A representative inhibition of colony formation by $D L E C I$ through monolayer culture assay is shown in the left panel. Ectopic $D L E C I$ expression was determined by RT-PCR and quantitative analyses of colony numbers are shown in the right panel. Values are the mean \pm s.d. of three independent experiments. $* * P<0.01$.

ectopic expression of DLEC1 significantly suppressed colorectal and gastric carcinoma cell clonogenicity. Our results indicated that DLEC1 is a functional TSG for CRC and gastric cancers, but is frequently inactivated by methylation-mediated silencing in these tumours.

Given the critical role of DNA methylation in the inactivation of TSGs as well as its potential application as tumour biomarkers for cancer diagnosis and prognosis assessment, various genome-wide techniques have been developed to screen for methylated genes in cancer cells. Among them, one is MS-RDA, which has been successfully used to identify methylated targets in multiple tumours (Kaneda et al, 2003; Ying et al, 2005). We used an improved MS-RDA to identify methylated targets in HCT116 comparing with DKO, in which virtually all known epigenetically silenced TSGs were reactivated with demethylation ( $\mathrm{Paz}$ et al, 2003). The re-identification of multiple genes that had been shown earlier to be methylated in tumours represented a successful validation of this approach (Ying and Tao, manuscript in preparation). Considering promoter CGI and the chromosome location of identified genes, among the 22 targets identified, one regarded to be of particular interest is DLEC1 (Daigo et al, 1999), which is located at the commonly deleted locus 3 p22.3 and recently reported to be methylated in lung, ovarian and nasopharyngeal carcinomas (Kwong et al, 2006, 2007). Here, we provided solid evidence that DLEC1 is also frequently methylated and acts as a functional TSG in CRC and gastric cancers.

Frequent deletion of $3 p$ is one of the earliest molecular changes in tumours of the lung, nasopharynx, oesophagus, kidney, head and neck, breast, cervix and gastrointestinal tract (Hung et al, 1995; Kok et al, 1997; Wistuba et al, 2000; Hesson et al, 2007). Identification of TSGs in the gene-rich 3 p22 -21.3 region has been challenging, although several candidate TSGs within this region showed tumour suppressor functions, such as RASSF1A (Pfeifer et al, 2002), SEMA3B (Tomizawa et al, 2001), BLU/ZMYND10 (Qiu et al, 2004), FUS1 (Zabarovsky et al, 2002) and HYA22 (RBSP3) (Kashuba et al, 2004), with some of them (RASSF1A and BLU) frequently inactivated by promoter methylation-mediated silencing. DLEC1, also located at this region, contains 37 exons, spans $\sim 59 \mathrm{~kb}$ and encodes a 1755 -amino-acid protein. DLEC1 was first identified as a potential TSG involved in lung, oesophageal and renal cancers, but with no methylation detected (Daigo et al, 1999). Recently, DLEC1 was reported to be frequently downregulated by methylation in ovarian and nasopharyngeal cancer (Kwong et al, $2006,2007)$. Together with our results of DLEC1 methylation in CRC and gastric cancers, DLEC1 is likely to be inactivated in a wide range of tumours by promoter methylation and plays an important role in multiple tumorigenesis.

The function of DLEC1 was further explored by examining the inhibitory effect of DLEC1 expression on tumour cell growth. Introduction of DLEC1 to silenced tumour cell lines HCT116 and MKN45 strongly suppressed their growth in colony formation assays. Similar tumour-suppressive properties were observed in oesophageal, renal and lung cancer cell lines (Daigo et al, 1999; Kwong et al, 2006). The proliferation and invasiveness of DLEC1expressing cells were also greatly reduced with a dramatic reduction in tumorigenic potential in in vivo animal models (Kwong et al, 2007). These findings support that DLEC1 is a functional TSG involved in multiple tumorigenesis; however, the mechanism underlying this role remains largely unknown. The predicted protein sequence of DLEC1 has no significant homology to any known proteins or domains. Earlier report showed that 27 potential CK2 (formerly known as casein kinase II) phosphorylation sites are present in its predicted sequence (Daigo et al, 1999). Protein kinase CK2 is a pleiotropic, ubiquitous, constitutively active and second message-independent protein kinase and known to phosphorylate more than 100 substrates, many of which are involved in the control of cell division, signal transduction and many other cellular functions (Litchfield, 2003). CK2 is required at multiple transition in the cell cycle, including G0/G1, G1/S and G2/M (Litchfield, 2003), indicating that DLEC1 may be one of the increasing CK2 targets, modulated by CK2 and involved in cell cycle arrest.

Although DLEC1 methylation has been shown to be associated with tumour stages in hepatocellular carcinoma (Qiu et al, 2008), we did not find any correlation between DLEC1 methylation and clinical parameters in gastric tumours. A further larger scale study is needed to confirm this negative finding.

Tumour-specific promoter methylation can serve as a biomarker for tumour early diagnosis. The tumour-specific methylation of $D L E C 1$ in CRC and gastric cancers indicates that it could be used for such purposes in future. Our results revealed a higher frequency of methylation in cell lines $(83-100 \%)$ but lower in primary tumours $(29-34 \%)$, indicating that some cell lines may have acquired methylation during their establishment or maintenance process. Similar phenomenon has been reported for some other TSGs in other tumours as well (Smiraglia et al, 2001; Paz et al, 2003; Ying et al, 2005).

In summary, we found that DLEC1 is frequently silenced by promoter methylation in colorectal and gastric cancers in a tumour-specific manner. We also showed that the methylationmediated silencing of DLEC1 could be reversed by genetic or 
pharmacologic demethylation, and restoration of DLEC1 suppressed tumour cell clonogenicity, providing significant evidence that DLEC1 functions as a tumour suppressor in these tumours. It would thus be worthy further exploring the possible use of DLEC1 methylation as an epigenetic biomarker for molecular diagnosis.

\section{ACKNOWLEDGEMENTS}

We thank Dr Bert Vogelstein for HCT116 cells with knockout of DNMTs, Dr Keith Robertson for DNA samples of some CRC cell lines and the Chinese University of Hong Kong for the support.

\section{REFERENCES}

Daigo Y, Nishiwaki T, Kawasoe T, Tamari M, Tsuchiya E, Nakamura Y (1999) Molecular cloning of a candidate tumor suppressor gene, DLC1, from chromosome 3p21.3. Cancer Res 59: 1966-1972

Esteller M, Risques RA, Toyota M, Capella G, Moreno V, Peinado MA, Baylin SB, Herman JG (2001) Promoter hypermethylation of the DNA repair gene $\mathrm{O}(6)$-methylguanine-DNA methyltransferase is associated with the presence of $\mathrm{G}: \mathrm{C}$ to $\mathrm{A}: \mathrm{T}$ transition mutations in $\mathrm{p} 53$ in human colorectal tumorigenesis. Cancer Res 6: 468-469

Gardiner-Garden M, Frommer M (1987) CpG islands in vertebrate genomes. J Mol Biol 196: $261-282$

Herman JG, Umar A, Polyak K, Graff JR, Ahuja N, Issa JP, Markowitz S, Willson JK, Hamilton SR, Kinzler KW, Kane MF, Kolodner RD, Vogelstein B, Kunkel TA, Baylin SB (1998) Incidence and functional consequences of hMLH1 promoter hypermethylation in colorectal carcinoma. Proc Natl Acad Sci USA 95: 6870-6875

Hesson LB, Cooper WN, Latif F (2007) Evaluation of the 3p21.3 tumoursuppressor gene cluster. Oncogene 26: 7283-7301

Hung J, Kishimoto Y, Sugio K, Virmani A, McIntire DD, Minna JD, Gazdar AF (1995) Allele-specific chromosome 3p deletions occur at an early stage in the pathogenesis of lung carcinoma. JAMA 273: 558-563

Imreh S, Klein G, Zabarovsky ER (2003) Search for unknown tumorantagonizing genes. Genes Chromosomes Cancer 38: 307-321

Jin H, Wang X, Ying J, Wong AH, Li H, Lee KY, Srivastava G, Chan AT, Yeo W, Ma BB, Putti TC, Lung ML, Shen ZY, Xu LY, Langford C, Tao Q (2007) Epigenetic identification of ADAMTS18 as a novel 16q23.1 tumor suppressor frequently silenced in esophageal, nasopharyngeal and multiple other carcinomas. Oncogene 26: 7490-7498

Jones PA, Baylin SB (2002) The fundamental role of epigenetic events in cancer. Nat Rev Genet 3: $415-428$

Kaneda A, Takai D, Kaminishi M, Okochi E, Ushijima T (2003) Methylation-sensitive representational difference analysis and its application to cancer research. Ann N Y Acad Sci 983: 131 -141

Kashuba VI, Li J, Wang F, Senchenko VN, Protopopov A, Malyukova A, Kutsenko AS, Kadyrova E, Zabarovska VI, Muravenko OV, Zelenin AV, Kisselev LL, Kuzmin I, Minna JD, Winberg G, Ernberg I, Braga E, Lerman MI, Klein G, Zabarovsky ER (2004) RBSP3 (HYA22) is a tumor suppressor gene implicated in major epithelial malignancies. Proc Natl Acad Sci USA 101: $4906-4911$

Kim HC, Roh SA, Ga IH, Kim JS, Yu CS, Kim JC (2005) CpG island methylation as an early event during adenoma progression in carcinogenesis of sporadic colorectal cancer. J Gastroenterol Hepatol 20: $1920-1926$

Kinzler KW, Vogelstein B (1996) Lessons from hereditary colorectal cancer. Cell 87: $159-170$

Kok K, Naylor SL, Buys CH (1997) Deletions of the short arm of chromosome 3 in solid tumors and the search for suppressor genes. $A d v$ Cancer Res 71: 27 -92

Kwong J, Chow LS, Wong AY, Hung WK, Chung GT, To KF, Chan FL, Daigo Y, Nakamura Y, Huang DP, Lo KW (2007) Epigenetic inactivation of the deleted in lung and esophageal cancer 1 gene in nasopharyngeal carcinoma. Genes Chromosomes Cancer 46: 171-180

Kwong J, Lee JY, Wong KK, Zhou X, Wong DT, Lo KW, Welch WR, Berkowitz RS, Mok SC (2006) Candidate tumor-suppressor gene DLEC1 is frequently downregulated by promoter hypermethylation and histone hypoacetylation in human epithelial ovarian cancer. Neoplasia 8: 268-278

Leung WK, Yu J, Ng EK, To KF, Ma PK, Lee TL, Go MY, Chung SC, Sung JJ (2001) Concurrent hypermethylation of multiple tumor-related genes in gastric carcinoma and adjacent normal tissues. Cancer 91: 2294-2301

Litchfield DW (2003) Protein kinase CK2: structure, regulation and role in cellular decisions of life and death. Biochem J 369: $1-15$
Paz MF, Wei S, Cigudosa JC, Rodriguez-Perales S, Peinado MA, Huang TH, Esteller M (2003) Genetic unmasking of epigenetically silenced tumor suppressor genes in colon cancer cells deficient in DNA methyltransferases. Hum Mol Genet 12: 2209-2219

Pfeifer GP, Yoon JH, Liu L, Tommasi S, Wilczynski SP, Dammann R (2002) Methylation of the RASSF1A gene in human cancers. Biol Chem 383: $907-914$

Qiu GH, Salto-Tellez M, Ross JA, Yeo W, Cui Y, Wheelhouse N, Chen GG, Harrison D, Lai P, Tao Q, Hooi SC (2008) The tumor suppressor gene DLEC1 is frequently silenced by DNA methylation in hepatocellular carcinoma and induces G1 arrest in cell cycle. J Hepatol 48: $433-441$

Qiu GH, Tan LK, Loh KS, Lim CY, Srivastava G, Tsai ST, Tsao SW, Tao Q (2004) The candidate tumor suppressor gene BLU, located at the commonly deleted region $3 \mathrm{p} 21.3$, is an E2F-regulated, stress-responsive gene and inactivated by both epigenetic and genetic mechanisms in nasopharyngeal carcinoma. Oncogene 23: 4793-4806

Rhee I, Bachman KE, Park BH, Jair KW, Yen RW, Schuebel KE, Cui H, Feinberg AP, Lengauer C, Kinzler KW, Baylin SB, Vogelstein B (2002) DNMT1 and DNMT3b cooperate to silence genes in human cancer cells. Nature 416: $552-556$

Smiraglia DJ, Rush LJ, Fruhwald MC, Dai Z, Held WA, Costello JF, Lang JC, Eng C, Li B, Wright FA, Caligiuri MA, Plass C (2001) Excessive CpG island hypermethylation in cancer cell lines versus primary human malignancies. Hum Mol Genet 10: 1413-1419

Sugai M, Kondo S, Shimizu A, Honjo T (1998) Isolation of differentially expressed genes upon immunoglobulin class switching by a subtractive hybridization method using uracil DNA glycosylase. Nucleic Acids Res 26: $911-918$

Tao Q, Huang H, Geiman TM, Lim CY, Fu L, Qiu GH, Robertson KD (2002) Defective de novo methylation of viral and cellular DNA sequences in ICF syndrome cells. Hum Mol Genet 11: $2091-2102$

Tao Q, Swinnen LJ, Yang J, Srivastava G, Robertson KD, Ambinder RF (1999) Methylation status of the Epstein-Barr virus major latent promoter $\mathrm{C}$ in iatrogenic B cell lymphoproliferative disease. Application of PCR-based analysis. Am J Pathol 155: 619-625

Tomizawa Y, Sekido Y, Kondo M, Gao B, Yokota J, Roche J, Drabkin H, Lerman MI, Gazdar AF, Minna JD (2001) Inhibition of lung cancer cell growth and induction of apoptosis after reexpression of $3 \mathrm{p} 21.3$ candidate tumor suppressor gene SEMA3B. Proc Natl Acad Sci USA 98: $13954-13959$

Wistuba II, Behrens C, Virmani AK, Mele G, Milchgrub S, Girard L, Fondon JW, Garner HR, McKay B, Latif F, Lerman MI, Lam S, Gazdar AF, Minna JD (2000) High resolution chromosome 3p allelotyping of human lung cancer and preneoplastic/preinvasive bronchial epithelium reveals multiple, discontinuous sites of $3 \mathrm{p}$ allele loss and three regions of frequent breakpoints. Cancer Res 60: 1949-1960

Ying J, Li H, Seng TJ, Langford C, Srivastava G, Tsao SW, Putti T, Murray P, Chan AT, Tao Q (2006) Functional epigenetics identifies a protocadherin PCDH10 as a candidate tumor suppressor for nasopharyngeal, esophageal and multiple other carcinomas with frequent methylation. Oncogene 25: $1070-1080$

Ying J, Srivastava G, Hsieh WS, Gao Z, Murray P, Liao SK, Ambinder R, Tao Q (2005) The stress-responsive gene GADD45G is a functional tumor suppressor, with its response to environmental stresses frequently disrupted epigenetically in multiple tumors. Clin Cancer Res 11: $6442-6449$

Zabarovsky ER, Lerman MI, Minna JD (2002) Tumor suppressor genes on chromosome $3 \mathrm{p}$ involved in the pathogenesis of lung and other cancers. Oncogene 21: 6915-6935 